\title{
Pyogenic granuloma-a 19 months follow up case report.
}

\author{
*Md. Ashif Iqbal ${ }^{\text {a }}$, Jesmin Mohol ${ }^{\mathrm{b}}$, Md. Saifur Rahman ${ }^{\mathrm{c}}$, Fayeza Afrin ${ }^{\mathrm{d}}$ \\ a. Assistant Professor, Department of Oral Pathology \& Periodontology, Update Dental College \& Hospital, Dhaka \\ b. Lecturer, Department of Oral Pathology \& Periodontology, Update Dental College \& Hospital, Dhaka \\ c. Medical Officer, Department of Oral Pathology \& Periodontology, Update Dental College \& Hospital, Dhaka \\ d. Lecturer, Department of Oral Pathology \& Periodontology, Update Dental College \& Hospital, Dhaka
}

\section{ARTICLE INFO}

Article history:

Received : 10.01 .15

Accepted : 24.02.15

\section{Key words:}

Pyogenic granuloma. Pregnancy, Treatment. Follow-up.

\begin{abstract}
Pyogenic granuloma is one of the inflammatory hyperplasia seen in the oral cavity. This term is a misnomer because the lesion is unrelated to infection and in reality arises in response to various stimuli such as low- grade local irritation, traumatic injury or hormonal factors. Clinically, oral pyogenic granuloma is a smooth or lobulated exophytic lesion manifesting as small, red erythematous papules on a pedunculated or sometimes sessile base, which is usually hemorrhagic. The surface ranges from pink to red to purple, depending on the age of the lesion. Because of the high frequency of pyogenic granuloma in the oral cavity, especially during pregnancy, and necessity for proper diagnosis and treatment, a complete information and investigations about this lesion, in addition its treatment is presented. The study emphasizes the clinical follow-up after the treatment of patients that present pyogenic granuloma. Follow-up over 19 months of surgical procedures demonstrated the maintenance of a periodontal health decreases the chances of recurrence.
\end{abstract}

\section{Introduction}

The pyogenic granuloma is a benign lesion of the gingival mucosa. These are generally associated with periodontal disease inflammatory and hormonal factors such as pregnancy $^{1-4}$. This lesion is characterized by localized polypoid growth, which is exophytic, sessile or pedunculated erythematous to brownish,and usually ulcerated with spontaneous bleeding.

\section{Address of Corresponding:}

* Dr. Md. Ashif Iqbal

Assistant Professor,

Dept. Oral Pathology \& Periodontology

Update Dental College, Dhaka

E-mail: drasif100@gmail.com

Cell: +88 01716116080
The surface of the oral pyogenic granuloma ranges from pink to red to purple, depending on the age of the lesion ${ }^{5}$. Hormones and other factors may modify the response and promote development of hyperplastic tissue or granulation. Hormonal changes in both the gestational period and puberty modify the clinical course ${ }^{6}$, since the levels of estrogen and progesterone is high, exerting a markedly enhanced proliferative effect at the level of the endothelium ${ }^{2}$.

The treatment usually used is surgical excision of the lesion, including all tissue where the disease appears. This is performed in combination with the removal of local irritating factors such as dental plaque and calculus ${ }^{4,5,7-9}$. However, recognition and identification of these factors are not always possible and the rate of recurrence of the injury is relatively high due to 
incomplete removal of the lesion or failure due to the intervention of etiological factors.

\section{Case report}

A 25-year-old female in the fourth month of pregnancy was referred to the Periodontology department of Update dental College \& Hospital. She presented a polypoid sessile gingival mass on the labial and palatal aspect of teeth 22 and 23.

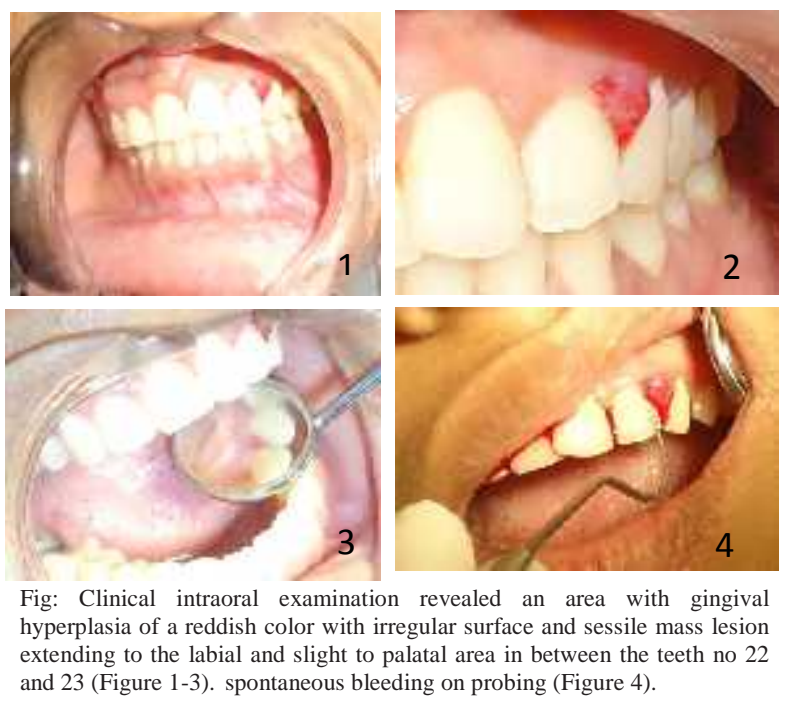

She also complained of profuse gingival bleeding upon brushing. Clinical intraoral examination revealed an area with gingival hyperplasia of a reddish color with irregular surface and sessile mass lesion extending to the labial and slight to palatal area in between the teeth no 22 and 23 (Figure 1-3).

Periodontal examination revealed a 5-mm pocket on the buccal and proximal aspects of $22 / 23$ and spontaneous bleeding on probing (Figure 4). Light presence of dental plaque was detected during initial clinical examination of the gingival margin, especially around the incisor area. The patient was sufficiently informed about her oral health status, as well as the proposed treatment, and signed a consent form that outlined the ethical and legal principles of clinical care.

After basic periodontal treatment, the gingival mass, which also involved the interproximal and labial aspects of teeth 22 and 23, was completely excised and submitted for histopathologic examination . (Figure 05-07) At the time of the procedure under local anesthesia with lidocaine $2 \%$ and 1:100,000 epinephrine. After removal of the lesion, the scraping technique was performed with currete and scalpel blade no-15, to restore the aesthetic contour of the affected gingival region. After surgical excision, the area was protected with zinc oxide cement (Figure 08). The patient was advised to use 0.2 percent chlorhexidine gluconate solution twice a day for ten days for periodontal maintenance.
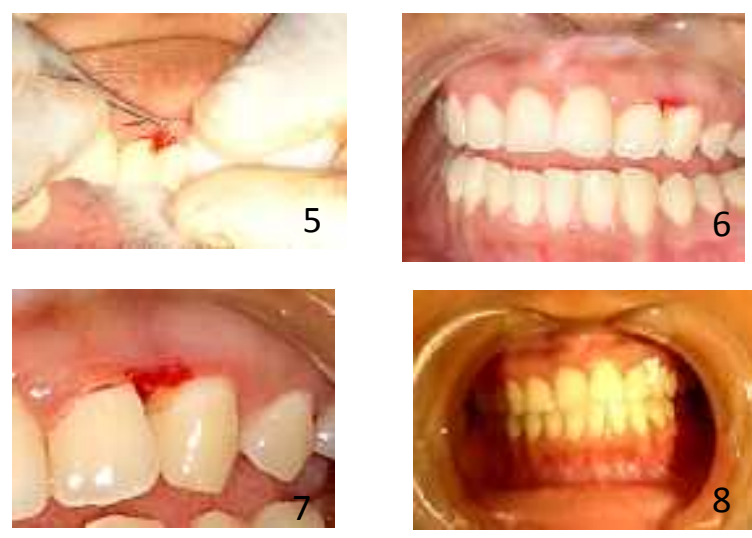

Fig: Surgical excision and area is protected with zincoxide eugenol cement. (Figure 5-8)

Histological analysis revealed the presence of vascular proliferation, and similar to granulation tissue, and chronic inflammatory cell infiltrate comprising neutrophils, plasma cells and lymphocytes (Figure 09)

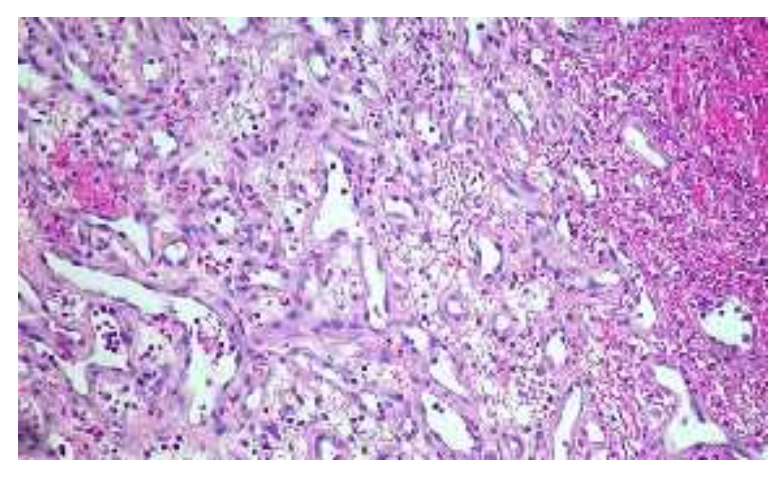

Figure: 09: Showing Histolpathological features of pyogenic granuloma.

After one weeks, the gingival tissue showed a beginning of healing within the expected 
normality (Figure 10). After two months of the periodontal surgery, Gingival tissue show approximately normal in feature and was noted the symmetry with right side . (Figure 11-13).

It was determined that the patient could maintain adequate plaque control. After six months of healing, the patient was pleased with the aesthetic results that addressed and at the 19 months postoperative visit, the periodontium and anterior dentition appeared to be healthy, and there was no recurrence of the pyogenic granuloma . A follow-up examination showed satisfactory resolution of the clinical case and suggested a favorable progression in the periodontal tissues involved. (Figure 14-15)
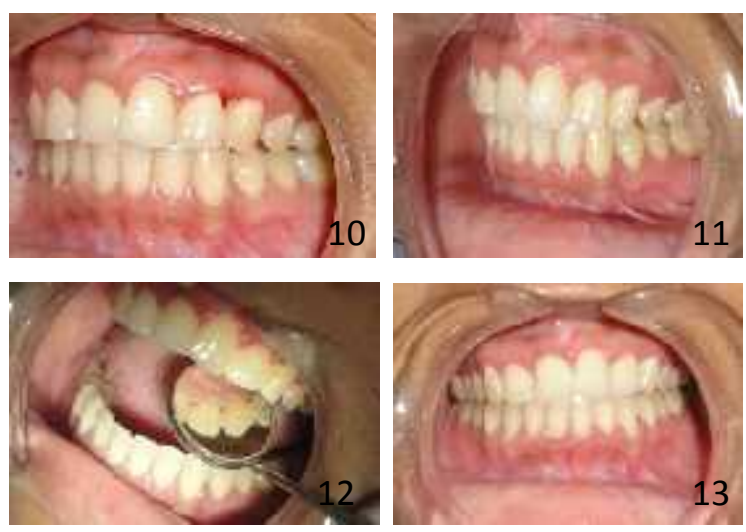

Figure: After 1 weeks, the gingival tissue showed a beginning of healing within the expected normality (Figure 10). After two months of the periodontal surgery, Gingival tissue show approximately normal in feature and was noted the symmetry with right side. (Figure 11-13).

\section{Discussion}

Pyogenic granuloma that develops in pregnant women. The condition typically occurs in the first trimester of pregnancy and rapid growth follows the steady increase in circulating estrogen and progesterone(1-4). About $50 \%$ of pregnant women have gingival changes, althoughonly a small proportion develop tumors in the gingival tissue ${ }^{10}$. Atypical situations may be observed, such as a pyogenic granuloma concomitant with drug-induced gingival hyperplasia in renal transplant patients under cyclosporin therapy or, alternately, in association with external dental resorption ${ }^{11-12}$.

Whitaker SB, Bouquot JB, Alimaro AE, Withaker TJ showed in their study that the gingival tissue has receptors for steroid hormones ${ }^{2}$ and thus the increasein estrogen and progesterone can cause changes in the physiology of gingival tissue ${ }^{1}$. Such changes can enhance the response of gingival tissues to local irritants such as plaque and calculus. In this case, the clinical examination showed low, however present, accumulation of plaque and a small amount of tartar on the teeth, mainly related to the lesion. Presumptive clinical diagnosis was pyogenic granuloma, taking into account the clinical features of the lesion. It should be noted that the definitive diagnosis of lesions in oral soft tissues can only be made after histopathological examination which, in this case, confirmed the diagnosis ${ }^{4}$.
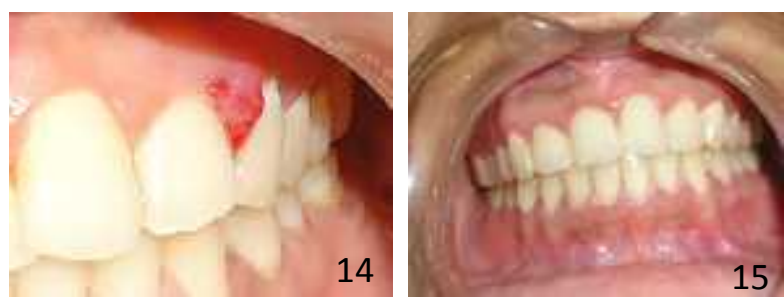

Figure: Initial lesion and 19 months after the surgical excision (Fig.-14 -15)

In the case of a benign lesion, adequate excision usually leads to cure ${ }^{9}$. To prevent the recurrence predisposing factors for the lesion should be removed ${ }^{4}$. Periodic preventive maintenance is essential for periodontal health in the long-term. Therefore, one can conclude that the therapy used in this case has the potential to achieve a framework of periodontal health. Therefore the patient was fully treated to facilitate the control of systemic conditions, surgical removal of the lesion and appropriate periodontal health management.

\section{Conclusion}

The pyogenic granuloma is a relatively common, tumorlike, exuberant tissue response to localized irritation. It is a reactive inflammatory process filled with proliferating vascular channels, immature fibroblastic connective tissue, and scattered inflammatory cells. The clinical treatment protocol is based on surgical excision and histopathological confirmation. Pregnancy itself is not the etiology of this kind of lesion. During pregnancy local factors may aggravate 
this. So proper oral hygiene maintenance is requirement for good periodontal health during pregnancy.

\section{References}

1. Ojanotko-Harri AO, Harri MP, Hurttia HM, Sewon LA. Altered tissue metabolism of progesterone in pregnancy gingivitis and granuloma. J Clin Periodontol. 1991;18(4):262-6.

2. Whitaker SB, Bouquot JB, Alimaro AE, Withaker TJ. Identification and semiquantification of estrogen and progesterone receptors in pyogenic granulomas of pregnancy. Oral Surg Oral Med Oral Pathol. 1994;78(6):755-60.

3. Fowler EB, Cuenin MF, Thompson SH, Kudryk VL,Billman MA. Pyogenic granuloma associated with guided tissue regeneration: a case report. J Periodontol. 1996;67(10):1011-5.

4. Cruz LE, Martos J. Granuloma gravidarum (pyogenic granuloma) treated with periodontal plastic surgery.Int J Gynaecol Obstet. 2010;109(1):73-4.

5. Jafarzadeh H, Sanatkhani M, Mohtasham N. Oral pyogenic granuloma: a review. J Oral Sci. 2006;48(4):167-75.

6. Yuan K, Wing LY, Lin MT. Pathogenic roles of angiogenic factors in pyogenic granulomas in pregnancy are modulated by female sex hormones. J Periodontol. 2002;73(7):701-8.

7. Terezhalmy GT, Riley CK, Moore WS. Pyogenic granuloma (pregnancy tumour). Quintessence Int. 2000;31(6):440-1.

8. Silva-Sousa YTC, Coelho CMP, Brentegani LG, Vieira MLSO, Oliveira ML. Clinical and histological evaluation of granuloma gravidarum: case report. Braz Dent J. 2000;11(2):135-9.

9. Bosco AF, Bonfante S, Luize DS, Bosco JM, Garcia VG. Periodontal plastic surgery associated with treatment for the renoval of gingival overgrowth. J Periodontol 2006;77(5):922-8.

10. Silverstein LH, Burton CH, Garnick JI, Singh BB. The late development of oral pyogenic granuloma as acomplication of pregnancy: a case report. Compend Contin Educ Dent. 1996;17(2):1928.

11. Vélez LMA, Souza LB, Pinto LP, Al-Zayer M, Fonseca M, Ship JA. Pyogenic granuloma in a renal transplant patient: case report. Spec Care Dentist. 2001;21(5): 187-90.

12. Vossoughi R, Takei H. External cervical resorption associated with traumatic occlusion and pyogenic granuloma. J Canad Dent Assoc.

2007;73(7):625-8 